\title{
REVIEWS
}

\section{Photogrammetry and Its Potential Application in Medical Science on the Basis of Selected Literature}

\author{
Department of Dental Prosthetics, Pomeranian Medical University, Szczecin, Poland
}

A - research concept and design; $\mathbf{B}$ - collection and/or assembly of data; $\mathbf{C}$ - data analysis and interpretation;

$\mathbf{D}$ - writing the article; $\mathbf{E}$ - critical revision of the article; $\mathbf{F}$ - final approval of article; $\mathbf{G}$ - other

\begin{abstract}
Photogrammetry is a science and technology which allows quantitative traits to be determined, i.e. the reproduction of object shapes, sizes and positions on the basis of their photographs. Images can be recorded in a wide range of wavelengths of electromagnetic radiation. The most common is the visible range, but near- and mediuminfrared, thermal infrared, microwaves and X-rays are also used. The importance of photogrammetry has increased with the development of computer software. Digital image processing and real-time measurement have allowed the automation of many complex manufacturing processes. Photogrammetry has been widely used in many areas, especially in geodesy and cartography. In medicine, this method is used for measuring the widely understood human body for the planning and monitoring of therapeutic treatment and its results. Digital images obtained from optical-electronic sensors combined with computer technology have the potential of objective measurement thanks to the remote nature of the data acquisition, with no contact with the measured object and with high accuracy. Photogrammetry also allows the adoption of common standards for archiving and processing patient data (Adv Clin Exp Med 2015, 24, 4, 737-741).
\end{abstract}

Key words: photogrammetry, image reconstruction, orthopedics, dermatology, forensic medicine, dentistry.

Photogrammetry is a field of science and technology dealing with the acquisition, accumulation and transformation of information about the shape of an object, its location against other objects in space, and its movement or deformation [1]. The very name photogrammetry comes from three Greek words: photo (light), gramma (record), and metreo (measure). In short, this means recording and measuring with the use of light. Photogrammetric images can be made in various wavelengths of electromagnetic radiation. The most common is the visible range, but near- and medium-infrared, thermal infrared, microwaves and X-rays are also used. Images are recorded by sensors suitable for a given type of radiation. Cameras and scanners are used for the visible and infrared bands, while special receivers and radars for microwaves, and special X-ray cameras for X-rays [2].

Photogrammetric techniques used to be limited by the expense and specialization of the equipment, the operation of which required suitable knowledge and skills. Developments in IT, improvements in the quality of equipment, and a reduction in costs, have all contributed to the increased use of photogrammetry [3]. Digital images obtained from optical-electronic sensors combined with computer technology have the potential of objective measurement thanks to the remote nature of the data acquisition, with no contact with the measured object and with high accuracy. Further advantages of photogrammetric methods include the possibility of examining a great variety of objects and phenomena, including dynamic processes. Digital image processing and real-time measurement allow the automation of many complex manufacturing processes $[1,4,5]$.

Photogrammetric techniques are used on a large scale in geodesy. Photogrammetric images used in bar and photographic maps are widely used in agriculture, drainage work, forestry, and 
construction on land and water. Photogrammetry has revolutionized map-making. Dimensional terrain models obtained using stereoscopic images are of particular importance in initial studies in spatial planning, environmental protection and many technical projects. Three-dimensional reconstruction of an object is currently a very fashionable form of presentation in architectural documentation [6-9].

\section{Medical Applications of Photogrammetry}

In medicine, photogrammetry has gained popularity as a method of repeatable reproduction of body structures for the planning and monitoring of therapeutic treatment and its results [10]. Currently, photogrammetric methods are used most frequently in orthopedics. They allow quick measurements of an entire body or its parts, e.g. in screening tests of spinal curvatures [2, 11-14]. In a study by Saad et al., 20 patients aged 11-44 years with idiopathic scoliosis were photographed in the frontal and the sagittal plane to examine their anatomical landmarks in the acromion, the inferior angle of the scapula, anterior superior and posterior superior iliac spines, and the lateral malleolus. The conclusions emphasized the reliability of photogrammetric techniques in their study of posture [15]. Rodriques et al. conducted a comparative study of 12 women aged 65-74 with diagnosed osteoporosis and osteopenia, as well as healthy women. Twelve women of mean age 68.5 years were evaluated and divided into 2 groups. Group 1 consisted of 6 women with a densitometry diagnosis of spinal osteoporosis, while group 2 consisted of 6 women with a densitometry diagnosis of spinal osteopenia. These groups were compared with young adults. The 2 groups were photographed in the right sagittal plane. To measure the degree of thoracic kyphosis, perpendicular skin markers were placed on the spinous process of the $7^{\text {th }}$ cervical vertebra (C7) and on the $12^{\text {th }}$ thoracic vertebra (T12). Their results indicate that osteoporosis increases the degree of thoracic kyphosis, while their conclusions emphasized the superiority of non-invasive photogrammetry over the X-ray analysis of the curvatures of the spine, which exposed patients to radiation while providing low quality images [16].

Posture screening in children is usually performed using relatively cheap and easy to use devices based on moiré projection methods. The moiré method involves performing photographs of bright and dark stripes displayed on the object that are formed by superimposing of 2 line families onto each other. A network of lines placed between the object and 2 different light sources projects onto the object 2 superimposing shades. Given the distances of light sources from the object and of the network from the object as well as dimensions of the line, object shape can be reconstructed. A patient with scoliosis has a characteristic difference between the contour lines of the 2 halves of the body $[2,17,18]$. The resulting images also allow for the assessment of the progress of treatment $[16,17]$. In a study by Drzał-Grabiec and Szczepanowska-Wołowiec the posture of children aged 7-9 years was assessed using a photogrammetric method and was based on the moiré phenomenon. The study identified the dominant lordosis (subtype L1) and compared 24 parameters differentiating the type of posture and height-weight ratios [17].

Analysis of joint prosthesis abrasion is necessary to determine the cause of a failure of an implant or in predicting the duration of its use. The assessment of the degree of wear of orthopedic implants also uses photogrammetric methods, next to radiographic and gravimetric methods [19].

Photogrammetry has also been used in ophthalmology [20-22]. Romano, in his study based on fundus photography, developed a simple diagnostic method for identifying the under-development of the optic nerve which can be used for children. The author studied 16 eyes with clinically identified retardation and 55 healthy eyes. He measured the diameter of the optic disc. "For the normal series of eyes, the mean optic disc horizontal image diameter was $3.88 \mathrm{~mm}$, with a range of 3.44 to $4.70 \mathrm{~mm}$. For the series of eyes with optic nerve hypoplasia, the mean horizontal diameter was $2.64 \mathrm{~mm}$, with a range of 1.80 to $3.27 \mathrm{~mm}$. In subjects with no major ametropia $(<2.5$ diopters of spherical or cylindrical refractive error), a 3.4-mm horizontal diameter optic disc image on a $35-\mathrm{mm}$ transparency can be used as a clinical guide or dividing line for the diagnosis of optic nerve hypoplasia" [23]. According to Takamoto and Schwartz, the photogrammetric technique of measuring the thickness of the retinal nerve fiber layer can be a repeatable and valuable method for early diagnosis of glaucoma and other optic neuropathies, and also in monitoring the progress of damage to the retina [24].

In dermatology, photogrammetry can be used to examine the surface of the skin. According to Ding et al., it may facilitate the early diagnosis of melanoma. The authors compared the 3D images in 11 cases of skin melanoma plus 28 cases of benign changes (dermatofibroma, intradermal nevus, hyperkeratotic squamous papilloma, compound nevus, seborrhoeic keratoses, dysplastic 
nevus, congenital nevus and junctional nevus) with the images of healthy skin. Disorders of the skin texture were higher in melanoma compared to benign changes [25]. In monitoring the progress of healing and in the assessment of the efficacy of treatment used for chronic skin ulcers, it is important to analyze the size of wounds. The photogrammetric method eliminates manual measurement errors caused by difficulties in the objective assessment of the wound borders. It is easy to use and cheap, does require contact, saves time and is reliable [26-28].

In forensic analysis, the exact analysis of damage to hard and soft tissues is important for assessing the manner and cause of death. A limitation of the previously used radiodiagnostic method, i.e. scanning electron microscopy, was based on problems with comprehensive evaluation of large wounds $[29,30]$. Sansoni et al. analyzed traumatic traces in 3 forensic cases: abrasions of soft tissues in lower limbs in a traffic accident victim, blunt head injuries caused by a strike with a metal rod, and knife marks on the right femur. The study used a laser scanner and software converting data sets in the form of a cloud of points in a threedimensional model of the object. Test time was $10 \mathrm{~s}$. The images were used to evaluate the shape and depth of wounds. According to the authors, this type of $3 \mathrm{D}$ analysis can provide information about the direction, strength and speed with which the injury occurred, and also allow a comparison of wound morphology with the shape of the tool. This method can be used directly by the pathologist at the crime scene. The resultant 3D image can be converted to stereolithography. Merging data from a photogrammetric examination of the surface with computed tomography (CT) and nuclear magnetic resonance (NMR) images of internal organs gives the possibility of a complete analysis before a post-mortem examination [29]. Another application of photogrammetry is the visualization of bite marks, which allows for a very precise matching of the wound shape and individual characteristics of the culprit's teeth $[31,32]$.

In dentistry as well, the non-invasive technique of photogrammetry has been used to study the morphology of the facial skeleton. Motta et al. used photogrammetry to assess the relations between head posture and the incidence of bruxism in young children. Forty-two children aged between 3 and 6 years, with complete deciduous dentition, participated in the study. Twenty-one children diagnosed with bruxism according to the diagnostic criteria of the American Academy of Sleep Medicine were selected for the bruxism group, and 21 children without bruxism were selected for the control group. Markers were placed on 3 anatomical landmarks (spinous process of the $7^{\text {th }}$ cervical vertebra, manubrium of the sternum and mental protuberance) and photographic measurements were made to evaluate head posture. Children with bruxism showed greater changes in head posture than healthy children [33].

Three-dimensional imaging has many applications in orthodontics and orthognathic and reconstructive surgery [34-36]. This technique can also be used in longitudinal studies to show changes in facial softtissue morphology at different time intervals and to monitor closely growth disturbances and deviations from normal growth. Kau et al. described a 9-year old patient who had undergone segmental resection of the left side of the mandible with preservation of the condylar head due to juvenile aggressive fibromatosis. Immediate reconstruction of the defect was made by using a 2.4-mm syntheses titanium reconstruction plate fixated with 8 screws placed in the head and neck of the left condyle for rigid fixation. Several bone markers were placed at the time of operation for monitoring mandibular growth and its displacement vectors. Three-dimensional surface scans with the $3 \mathrm{dMDface}$ system were taken at several follow up times: immediately after resection, 6 months after resection, and 2 years after resection to monitor and evaluate the soft-tissue changes during dentofacial growth and the changes in the mandibular growth pattern after resection. This method of analysis has helped to define a great dilemma in the approach to future management and rehabilitation of the patient [37].

Craniofacial photographic analysis has also been used by Lee et al. to predict obstructive sleep apnea (OSA). One hundred eighty subjects (43 women and 137 men), with their ages ranging between 20 and 86 years, were evaluated. Clinical assessment, craniofacial photographic analyses and polysomnography were performed. "Frontal and profile photographs of the head and neck were obtained with a standardized setup using a single-lens reflex digital camera". Obstructive sleep apnea was found in 114 patients. "The photographic measurements identified in the logistic regression models appear to capture a range of anatomical risk factors for OSA. These include general and regional obesity (face width), fat deposition on the anterior neck (cervicomental angle), mandibular deficiency (mandibular length), and possibly inferior hyoid position (cervicomental angle)" [38]. Craniofacial photographic analysis technique may have a potential role as a research and diagnostic tool in epidemiological study and clinical practice $[39,40]$.

The authors have concluded that modern digital image processing methods allow the high reproducibility and objectivity of results. They are 
strong competition for other previously used methods. Photogrammetric measurement techniques are being increasingly used in medicine. They allow for the recording and comparative assessment of various phenomena in human tissues. They also make it possible to adopt common standards for data and image archiving. The patient data can be easily compressed, transferred and encoded.

\section{References}

[1] Jiang R, Jauregui DV, White KR: Close-range photogrammetry applications in bridge measurement: Literature review. Measurement 2008, 41, 823-834.

[2] Tokarczyk R, Mazur T: Photogrammetry - principles of operation and application in rehabilitation. Med Rehabil 2006, 10, 30-39.

[3] Pilgrim LJ: History of photogrammetry in medicine. Australas Phys Eng Sci Med 1992, 15, 1-8.

[4] Bosemann W: Advances in photogrammetric measurement solutions. Comput Ind 2005, 56, 886-893.

[5] Luhmann T: Close range photogrammetry for industrial applications. ISPRS P\&RS 2010, 65, 558-569.

[6] Alshawabkeh Y: A new true ortho-photo methodology for complex archaeological application. Archaeometry 2010, 52, 517-530.

[7] Ducke B, Score D, Reeves J: Multiview 3D reconstruction of the archaeological site at Weymouth from image series. Comput Graph 2011, 35, 375-382.

[8] Kucukkaya AG: Photogrammetry and remote sensing in archeology. J Quant Spectrosc Radiat Transfer 2004, 88, 83-88.

[9] Verhoeven G, Doneus M, Briese CH, Vermeulen F: Mapping by matching: a computer vision-based approach to fast and accurate georeferencing of archaeological aerial photographs. J Archaeol Sci 2012, 39, 2060-2070.

[10] Patias P: Medical imaging challenges photogrammetry. ISPRS P\&RS 2002, 56, 295-310.

[11] Figueiredo RV, Amaral AC, Shimano AC: Photogrammetry on the identification of postural asymmetries in cadets and pilots of the Brazilian air force academy. Rev Bras Fisioter 2012, 16, 54-60.

[12] Gabor LR, Chamberlin AP, Levy E, Perry MB, Cintas H, Paul SM: Digital stereophotogrammetry as a new technique to quantify truncal deformity: a pilot study in persons with osteogenesis imperfecta. Am J Phys Med Rehabil 2011, 90, 844-850.

[13] Mínguez MF, Buendía M, Cibrián RM, Salvador R, Laguía M, Martín A, Gomar F: Quantifier variables of the back surface deformity obtained with a noninvasive structured light method: evaluation of their usefulness in idiopathic scoliosis diagnosis. Eur Spine J 2007, 16, 73-82.

[14] Mitchell HL, Newton I: Medical photogrammetric measurement: overview and prospects. ISPRS P\&RS 2002, 56, 286-294.

[15] Saad KR, Colombo AS, Ribeiro AP, Joăo SM: Reliability of photogrammetry in the evaluation of the postural aspects of individuals with structural scoliosis. J Bodyw Mov Ther 2012, 16, 210-216.

[16] Rodrigues ACC, Romeiro CAP, Patrizzi LJ: Evaluation of thoracic kyphosis in older adult women with osteoporosis by means of computerized biophotogrammetry. Rev Bras Fisioter [online] 2009, 13, 205-209.

[17] Drzał-Grabiec J, Szczepanowska-Wołowiec B: Weight-height ratios and parameters of body posture in 7-9-yearolds with particular posture types. Ortop Traumatol Rehabil 2011, 13, 591-600.

[18] Porto F, Gurgel JL, Russomano T, Farinatti PT: Moiré topography: characteristics and clinical application. Gait Posture 2010, 32, 422-424.

[19] Sagbas B, Durakbasa MN: Measurement of Wear in Orthopedic Prosthesis. Acta Phys Pol A 2012, 121, 131-134.

[20] Azuara-Blanco A, Spaeth GL: Methods to objectify reversibility of glaucomatous cupping. Curr Opin Ophthalmol 1997, 8, 50-54.

[21] Pach J, Pennell DO, Romano PE: Optic disc photogrammetry: magnification factors for eye position, centration, and ametropias, refractive and axial; and their application in the diagnosis of optic nerve hypoplasia. Ann Ophthalmol 1989, 21, 454-462.

[22] Urs R, Manns F, Ho A, Borja D, Amelinckx A, Smith J, Jain R, Augusteyn R, Parel JM: Shape of the isolated ex-vivo human crystalline lens. Vision Res 2009, 49, 74-83.

[23] Romano PE: Simple photogrammetric diagnosis of optic nerve hypoplasia. Arch Ophthalmol 1989, 107, 824-826.

[24] Takamoto T, Schwartz B: Photogrammetric measurement of nerve fiber layer thicknes. Ophthalmology 1989, 96, $1315-1319$

[25] Ding Y, Smith L, Smith M, Sun J, Warr R: Obtaining malignant melanoma indicators through statistical analysis of 3D skin surface disruptions. Skin Res Technol 2009, 15, 262-270.

[26] Ahn C, Salcido RS: Advances in wound photography and assessment methods. Adv Skin Wound Care 2008, 21, 85-93.

[27] Bulstrode CJ, Goode AW, Scott PJ: Stereophotogrammetry for measuring rates of cutaneous healing: a comparison with conventional techniques. Clin Sci (Lond) 1986, 71, 437-443.

[28] Sprigle S, Nemeth M, Gajjala A: Iterative design and testing of a hand-held, non-contact wound measurement device. J Tissue Viability 2012, 21, 17-26.

[29] Sansoni G, Cattaneo C, Trebeschi M, Gibelli D, Porta D, Picozzi M: Feasibility of contactless 3D optical measurement for the analysis of bone and soft tissue lesions: new technologies and perspectives in forensic sciences. J Forensic Sci 2009, 54, 540-545. 
[30] Thali MJ, Braun M, Buck U, Aghayev E, Jackowski C, Vock P, Sonnenschein M, Dirnhofer R: VIRTOPSY - scientific documentation, reconstruction and animation in forensic: individual and real 3D data based geometric approach including optical body/object surface and radiological CT/MRI scanning. J Forensic Sci 2005, 50, 428-442.

[31] Ebert LC, Thali MJ, Ross S: Getting in touch - 3D printing in forensic imaging. Forensic Sci Int 2011, 211, 1-6.

[32] Thali MJ, Braun M, Markwalder TH, Brueschweiler W, Zollinger U, Malik NJ, Yen K, Dirnhofer R: Bite mark documentation and analysis: the forensic 3D/CAD supported photogrammetry approach. Forensic Sci Int 2003, $135,115-121$.

[33] Motta LJ, Martins MD, Fernandes KP, Mesquita-Ferrari RA, Biasotto-Gonzalez DA, Bussadori SK: Craniocervical posture and bruxism in children. Physiother Res Int 2011, 16, 57-61.

[34] Jayaratne YS, Lo J, Zwahlen RA, Cheung LK: Three-dimensional photogrammetry for surgical planning of tissue expansion in hemifacial microsomia. Head Neck 2010, 32, 1728-1735.

[35] Krimmel M, Schuck N, Bacher M, Reinert S: Facial surface changes after cleft alveolar bone grafting. J Oral Maxillofac Surg 2011, 69, 80-83.

[36] Wong JY, Oh AK, Ohta E, Hunt AT, Rogers GF, Mulliken JB, Deutsch CK: Validity and reliability of craniofacial anthropometric measurement of 3D digital photogrammetric images. Cleft Palate Craniofac J 2008, 45, 232-239.

[37] Kau CH, Kamel SG, Wilson J, Wong ME: New method for analysis of facial growth in a pediatric reconstructed mandible. Am J Orthod Dentofacial Orthop 2011, 139, 285-290.

[38] Lee RW, Petocz P, Prvan T, Chan AS, Grunstein RR, Cistulli PA: Prediction of obstructive sleep apnea with craniofacial photographic analysis. Sleep 2009, 32, 46-52.

[39] Lee RW, Chan AS, Grunstein RR, Cistulli PA: Craniofacial phenotyping in obstructive sleep apnea - a novel quantitative photographic approach. Sleep 2009, 32, 37-45.

[40] Woźniak K, Piątkowska D, Lipski M: The influence of natural head position on the assessment of facial morphology. Adv Clin Exp Med 2012, 21, 743-749.

\section{Address for correspondence:}

Małgorzata Chruściel-Nogalska

Chair and Department of Dental Prosthetics

Pomeranian Medical University

Powstańców Wlkp. 72

70-111 Szczecin

Poland

Tel.: +48914661715

E-mail: zd.protetyki.stom@pum.edu.pl

Conflict of interest: None declared

Received: 25.03 .2013

Revised: 6.05.2013

Accepted: 8.08.2015 